\title{
Atitudes de design e design estratégico: o desenvolvimento de um modelo teórico
}

\author{
Design attitude and strategic design: a theoretical model proposition
}

PAZ, Cesar. Mestre; Universidade do Vale do Rio dos Sinos (UNISINOS) cesarpaz64@gmail.com

COSTA, Filipe Campelo Xavier da. Doutor; Universidade do Vale do Rio dos Sinos (UNISINOS)

fcampelo@unisinos.br

BORBA, Gustavo Severo de. Doutor. Universidade do Vale do Rio dos Sinos (UNISINOS)

gborba@unisinos.br

\section{Resumo}

Este estudo tem como objetivo identificar e discutir a relação entre o conceito de atitude de design (design atitude) e a perspectiva do design estratégico. Foram analisadas as atitudes de design estratégico nos contextos organizacionais para refletir sobre quem é o designer estratégico e o que o caracteriza como um ser capaz de projetar estratégias organizacionais. Esse trabalho parte da abordagem do modelo de design atitude de Michlewski $(2008,2015)$, debatida e analisada a partir da visão de pesquisadores e doutores que investigam o design estratégico. Com os elementos construídos nesse diálogo, nasce o modelo ampliado de design atitude para o design estratégico, constituído de sete componentes que conformam as atitudes do designer estratégico.

Palavras Chave: design estratégico; design attitude; papel do designer.

\section{Abstract}

This study aims to identify and discuss the relationship between the design attitude concept and the strategic design approach. Strategic design attitudes were analyzed in organizational contexts to reflect on who is the strategic designer and what characterizes him as a being capable of designing organizational strategies. This work is based on the Michlewski's attitude design model (2008, 2015), debated and analyzed from the experts point of view'(PhD researchers who investigate strategic design). With the elements built in this dialogue, the expanded model of attitude design for strategic design is born, consisting of seven components that conform the attitudes of the strategic designer.

Keywords: strategic design; design attitude; designer role. 


\section{Introdução}

Nos últimos anos, a busca pela inovação, representada por desenvolvimento cada vez mais acelerado de produtos, serviços e processos, tem levado a discussão sobre design e o pensamento projetual para o contexto organizacional. Dentro do universo da inovação nas organizações, o design assume cada vez mais um papel importante sendo estudado por pesquisadores de distintas escolas de pensamento. Conforme Jacoby e Rodrigues (2008) o design thinking é um ativo crucial das empresas e base da inovação sistêmica pautada pelo viés humano, tecnológico e de negócios das organizações. Para Buchanan (2015), o pluralismo do design thinking pode atuar em diferentes dimensões dentro da estrutura organizacional, desde o processo cognitivo básico, passando pelo questionamento criativo, avançando na implementação de novos modelos até a transformação inovadora e criativa do espírito e da cultura da toda organização.

A cultura do design, da mesma forma que a cultura organizacional, evolui e se apresenta hoje como um sistema único de competências, habilidades, conhecimento e prática que pode auxiliar no processo de mudança, especialmente na transformação das organizações pela inovação e no processo de construção de estratégias organizacionais. (DESERTI; RIZZO, 2013). O design estratégico surge como uma das perspectivas de contribuição do design para os processos de abordagem estratégica nas organizações a partir dessa cultura de design, impulsionando a aprendizagem organizacional e como um guia para o desenvolvimento de estratégias corporativas (ZURLO, 1999).

Tendo como ponto de origem as pesquisas realizadas na década de 90 no Politécnico de Milão, o design estratégico é um campo importante na própria evolução da cultura do design. Um dos seus pilares está na visão sistêmica. De acordo com Zurlo (2010), na sociedade pós-moderna, caracterizada pela liquidez do seu sistema de valores, o design estratégico torna-se determinante para criar o sentido de agir na organização, que motiva todos os atores envolvidos na rede de projeto e os demais sujeitos que participam do projeto organizacional. Para Meroni (2008), o design estratégico de sistemas produto e serviço muda o foco da inovação do design de produtos ou serviços para o design da estratégia de uma solução integrada de produtos e serviços. Nesse contexto, surge a necessidade de entendermos quais são os papéis e as atitudes desse novo designer, com dimensões e aptidões estratégicas, nesse processo de evolução e nas organizações em transformação.

Quem é esse "designer estratégico" e suas características se constitui em uma lacuna teórica a ser preenchida. Meroni (2008) sugere que é um facilitador, capaz de catalisar e orientar a sensibilidade coletiva a favor de uma interpretação compartilhada de como será o futuro, se apropriando do que existe de melhor no presente e transformando isso por meio de novos paradigmas. Para Freire (2017), dependendo da situação, o designer estratégico pode assumir os seguintes diferentes papéis ao longo do processo criativo de design estratégico: antena, visionário, experimentador, conector e empreendedor como papéis possíveis. Franzato (2014) contextualiza as responsabilidades do designer estratégico afirmando que, diferente do planejamento estratégico, o designer estratégico não planeja, mas projeta as estratégias organizacionais. Franzato et al. (2015), analisa a potencialidade de ação do designer estratégico no âmbito dos coletivos criativos informais, o que se afasta em alguma medida da nossa proposta de pesquisa que se realiza no contexto amplo das organizações inovadoras.

Compreender essas capacidades e competências do designer remete a uma outra perspectiva que explora o impacto que o design e os designers têm nas organizações, cunhada como design atitude (atitude de design). Consiste em um conjunto de valores somados que caracterizam 
a natureza do designer e sua aplicação na sua ação diária, focada muito mais na cultura produzida pelos designers do que nos seus métodos. De acordo com Buchanan (2015), compreender as atitudes de design permite compreender os elementos que habilitam o processo criativo no design, bem como a natureza das contribuições dos designers e sua capacidade transformadora dentro das organizações.

O principal trabalho de pesquisa sobre o design attitude foi desenvolvido por Michlewski (2008). Depois de mais de dez anos de estudos e entrevistas com designers e líderes de empresas de sucesso em design como a Apple, Ideo, Nissan, o autor identificou cinco aspectos, todos ligados à cultura do design, que são realmente diferenciadores e que, reunidos, formam o modelo de design attitude. Os aspectos identificados são os seguintes: abraçando a certeza e a ambiguidade; engajando através da empatia profunda; abraçando o poder dos cinco sentidos; paixão por dar vida às ideias e criando novos significados a partir da complexidade.

Nesse estudo, o modelo de Michlewski $(2008,2015)$ serve de base para avançar em uma discussão que vai além da visão básica de quem seria o designer estratégico. Nos apoiamos no modelo de design attitude para evoluir a visão de atitudes do design estratégico, especialmente no ambiente das organizações, que são protagonistas nas novas morfologias da sociedade contemporânea e que, necessariamente, têm perfil inovador. Sendo assim, o objetivo desse trabalho é identificar as atitudes de design que caracterizam o designer estratégico. A partir de uma pesquisa de natureza exploratória junto a experts sobre o tema, pretende-se reunir elementos para a proposição de um modelo teórico de atitudes de design estratégico.

\section{Perspectivas sobre Design Estratégico}

No universo acadêmico, o design estratégico aparece como uma disciplina que tem sua matriz semiótica representada por discursos de diferentes áreas de pesquisa como a administração de negócios, a engenharia e o próprio design. $O$ termo surge com relevância no meio acadêmico a partir duas origens distintas. A primeira vem das escolas de Administração, pois as lideranças das organizações começaram a observar que o design thinking, ancorado na inovação e na visão empreendedora, pode ser aplicado e trazer soluções em situações que os modelos tradicionais da administração já não respondem. A partir disso, as novas teorias da Administração começaram a ser fortemente influenciadas pelas teorias do design e, especialmente, pelo conceito do design thinking.

O termo design estratégico vem sendo largamente utilizado para a definição de projetos no mundo corporativo ou em organizações de diferentes tipos. No contexto acadêmico ocorre o mesmo, mas pelo menos três pontos principais diferem a visão do design estratégico, nascido na Escola Politecnico de Milano, das visões do design estratégico ou termos muito próximos, conceituados nas escolas da Administração, espalhadas pelo mundo:

1. O paradigma da complexidade: o design estratégico é um processo de design que abraça o paradigma de complexidade para desenvolver, adaptar e envolver as estratégias organizacionais, o que permitirá que a organização se adapte às mudanças no contexto, sustentando-se a longo prazo (MAURI, 1996; ZURLO, 2010).

2. A ação na dimensão metaprojetual: segundo Scaletsky (2016), o design estratégico propõe a realização de pesquisas que têm por objetivo compreender melhor o problema de projeto e, se for o caso, reposicioná-lo. Nesse sentido, metaprojeto pode ser compreendido como um espaço que extrapola o próprio projeto, inserida na dinâmica em constante mutação, que caracteriza a complexidade do ato de projetar e que diferencia a etapa metaprojetual do design estratégico de 
outras formas de design. Conforme Moraes (2011), o metaprojeto surge como uma abordagem metodológica que dá suporte ao pensar no design estratégico. Na perspectiva do design estratégico, o problema não é o fator mais importante; ao contrário, o que é fundamental explorar é a possibilidade de projetar. Esta possibilidade está ligada às estratégias que serão adotadas para enfrentar tal problema. De fato, o designer reflete sobre as possíveis ações e preocupa-se em possibilitar caminhos de projetação. (MORAES, 2011).

3. O pensamento sistêmico e a sustentabilidade: considerado um dos eixos da construção do design de estratégias organizacionais. Colocar a noção de sistemas no centro da teoria do design estratégico significa compreendê-la como unidade complexa (ZURLO, 2010). A visão sobre a sustentabilidade, em um momento onde o mundo e a vida dão sinais de esgotamento, se funde com a visão sistêmica se tornando parte do pensamento estratégico contemporâneo. Segundo Franzato et al. (2015), o design estratégico enfatiza o estudo das estratégias elaboradas pelo design para orientar a ação projetual e, sobretudo, a ação organizacional em direção à inovação e à sustentabilidade. Essas estratégias são elaboradas por processos que envolvem todo o seu ecossistema de atuação: o meio organizacional, o mercado, a sociedade e o meio-ambiente.

$\mathrm{Na}$ evolução dos conceitos do design estratégico tem se falado pouco sobre o papel específico desse profissional, especialmente dentro das organizações. Quando abordado, é natural que exista alguma dificuldade de compreensão sobre a visão de planejamento estratégico, estratégias organizacionais e o design das estratégias organizacionais. Uma das escassas sobre o designer estratégico vem de Franzato, Velasques e Del Gaudio (2015) quando abordam as potencialidades de ação e de contribuição do designer estratégico no âmbito dos coletivos criativos informais - que certamente ainda estão distantes do contexto de nossa pesquisa que são as organizações com perfil inovador. Se as referências aos designers estratégicos são raras, existem referências ao papel dos designers que podem auxiliar a visão de definição de competências, atitudes ou habilidades que tenham relação com o designer estratégico dentro das organizações, como é o caso dos conceitos de Manzini $(2003,2014)$ para os designers facilitadores e designers experts.

Segundo Schön (1983), que fala sobre design em uma perspectiva da arquitetura, entre as qualidades genéricas do designer está primeiramente a condição de desenvolver um diálogo reflexivo com uma situação problema. Em sua visão, todos profissionais deveriam ter essa capacidade em algum nível. Nigel Cross é outro nome importante no debate sobre as habilidades do design. Ele entende que todos profissionais são designers e que todos têm, de alguma forma, habilidades de designer. (MICHELWSKI, 2015).

\section{Design Attitude}

Em junho de 2002, Richard Boland e Fred Collopy organizaram, na Weatherhead School of Management, a conferência Managing as Designing, aproveitando o grande interesse acadêmico sobre as possibilidades de aplicação do design thinking nas práticas de gestão de empresas e a recente experiência de trabalhar com o arquiteto Frank Gehry. Segundo os pesquisadores existia, naquele momento, uma crise relacionada ao esgotamento dos modelos de gestão nas organizações e, por consequência, também um campo fértil para evoluir na discussão sobre o design thinking e os modelos de formação de profissionais oriundos das Escolas de Administração. Esse novo olhar, na visão dos pesquisadores, poderia projetar ambientes e modelos organizacionais que fossem ao encontro de maior realização humana associada a um futuro sustentável. (BOLAND; COLLOPY, 2004).

Para Gehry e sua equipe no projeto acima relatado, existiu sempre o desejo de fazer algo 
extraordinário, experimentando o novo (materiais, tecnologias, métodos), característica comum a a todos os projetos liderados por Gehry. O desejo natural da sua equipe, para qualquer projeto, é o de fazer sempre algo melhor do que qualquer coisa que já tenha sido feita antes. Esse comportamento é definido por Boland e Collopy (2004) como design attitude porque se diferencia, de forma absoluta, dos clássicos modelos de gestão dentro das organizações. O conceito de design attitude faz com que o espírito empreendedor, que foi o coração da revolução industrial e informacional, esteja presente o tempo todo em projetos rentáveis e que produzem alto grau de satisfação humana para quem se envolve nele. (BOLAND; COLLOPY, 2004)

Michlewski (2008), buscando o entendido da natureza do design atitude, investigou valores e características que fundamentam a criatividade no design, explorando o que os designers e gestores/designers realmente dizem, fazem e como pensam a execução diária de seus trabalhos. Por meio de entrevistas com profissionais de nível sênior em empresas internacionalmente reconhecidas como líderes em processos de design (IDEO, Nissan Design, Philips Design e Wolf Olins), o autor revelou as formas de conhecimento dos designers, as habilidades que são exclusivas desse profissional e que são naturais na atividade de design.

Michlewski investigou os designers não apenas de forma individual, mas como grupo de profissionais e relacionando a natureza da contribuição deles às organizações. A análise em nível de grupo pode desembaraçar algumas das complexas questões associadas à cultura dos designers e seu impacto nos coletivos e estruturas organizacionais. Na base teórica do design attitude, Michlewski (2015) fornece evidências históricas sobre o significado do design, esclarece elementos que formam a cultura de design, examina a natureza dos designers e analisa a cultura dos profissionais de design, além das habilidades dos designers. A partir dessa análise, o autor define os cinco aspectos que compõem o design attitude e que impactam e transformam as organizações. São os seguintes os cinco aspectos que compõem o design attitude e a cultura dos designers profissionais:

1. Abraçando a incerteza e a ambiguidade: designers sabem que, quando decidem criar algo novo e completamente original, não existe garantia de sucesso. Eles têm consciência de que o processo de design é descontínuo e confuso.

2. Engajando através da empatia profunda: usar a verdadeira empatia requer coragem, honestidade e o desprendimento para abandonar os modelos mentais consagrados. Acima de tudo, precisam tratar os consumidores/usuários como reais seres humanos.

3. Abraçando o poder dos cinco sentidos: designers reconhecem que as melhores marcas e experiências são geradas a partir de vários sentidos com o propósito de criar um poderoso caminho neuronal que envolve reações como surpresa, prazer e reais emoções.

4. Paixão por dar vida às ideias: com o propósito de criar tração no processo de inovação, designers acreditam no poder da brincadeira, do humor e de uma saudável dose de subversão. Muitas vezes, utilizam a capa da criatividade - e aparente insanidade, projetada neles por outros profissionais - para questionar questões profundas e desafiar formas entrincheiradas de realizar coisas. Isso também os coloca em condições de tratar temas sensíveis que em organizações normais seriam evitados.

5. Criando novos significados a partir da complexidade: no jeito do designer fazer projetos está o desejo absoluto de engajar e reconciliar múltiplos, por vezes contraditórios, pontos de vista e fontes de informações de forma a produzir uma nova forma de pensar sobre alguma coisa, em diferentes níveis, inclusive estratégias. 
A representação gráfica do design attitude é mostrada na imagem a seguir:

Figura 1 - Modelo de Design Attitude

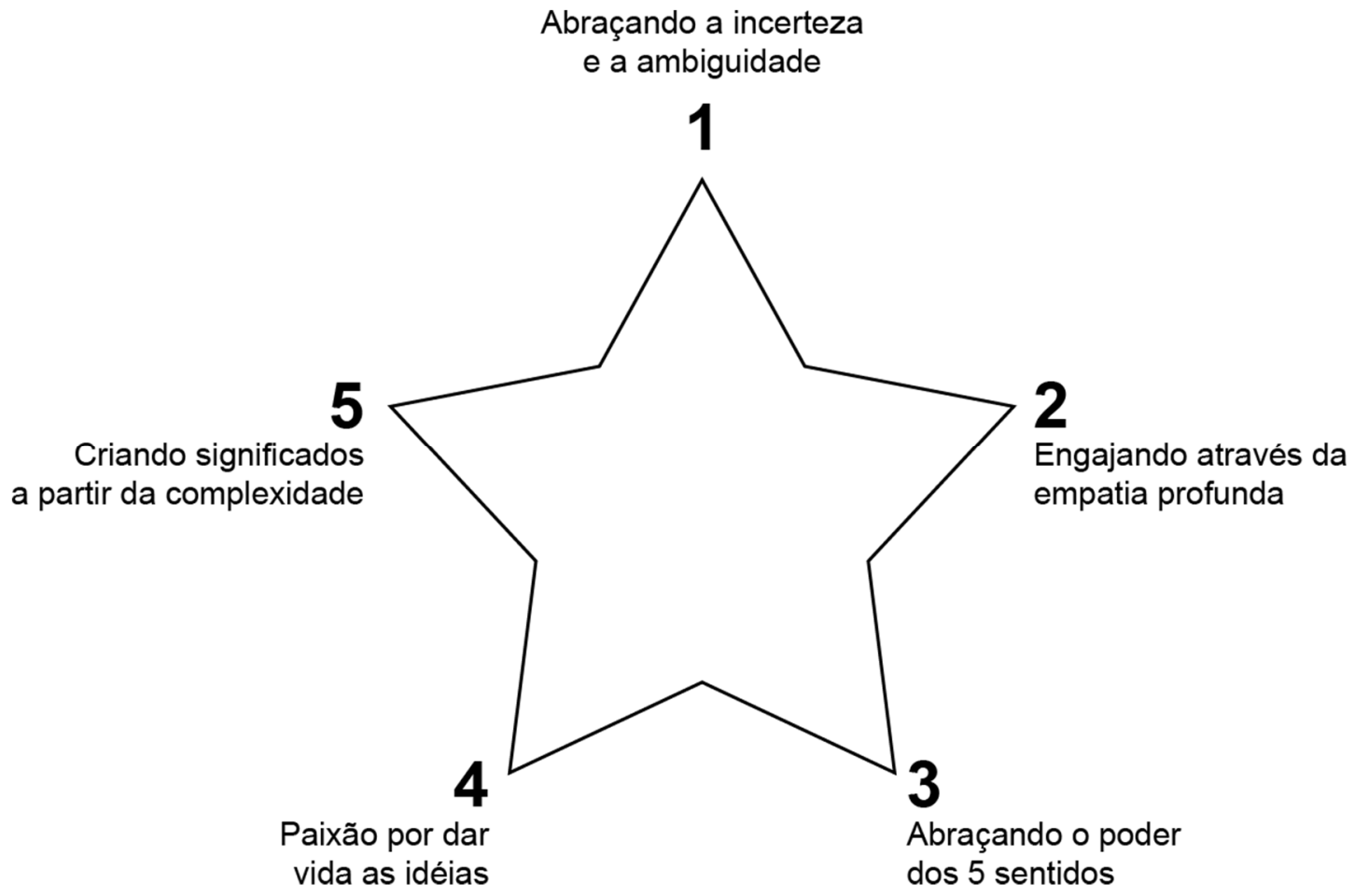

Fonte: Michlewski (2015).

Desde a publicação do The Science of Artificial, em 1969, Simon diz que todos somos designers, visto que aplicamos nosso intelecto para transformar as situações em que nos encontramos em situações em que queremos estar. O modelo do design attitude reforça essa visão na medida em que tangibiliza toda a natureza do design em uma matriz de polarização com cinco eixos formando o que Michlewski representa em suas publicações como uma estrela, que, em tese, pode ser aplicada em qualquer profissional de qualquer área para identificar atitudes de design.

\section{Procedimentos Metodológicos}

A proposta desse estudo é de natureza exploratória, a partir da realização de entrevistas em profundidade com especialistas sobre o tema design estratégico. 0 propósito dessa investigação junto a experts está na compreensão do possível diálogo entre modelo de design atittude proposto por Michlewski e a abordagem do design estratégico. Para tanto, foram identificados oito pesquisadores em design, atuantes em programas de pós-graduação na área e experiência de investigação sobre design estratégico como informantes para esse estudo. Todos os entrevistados possuem doutorado e possuem formações distintas (design, engenharia, psicologia, arquitetura, semiótica, etc.).

As entrevistas foram realizadas a partir de um roteiro de entrevista semi-estruturado e tendo seu áudio gravado, sendo o conteúdo posteriormente transcrito e analisado por meio da técnica de análise de conteúdo. $O$ roteiro empregado tinha como estrutura a apresentação dos princípios formadores do conceito de design atitude (Boland e Collopy, 2004), bem como a apresentação do 
modelo de Michlewski (2008, 2015). O objetivo dessa apresentação conceitual foi buscar equalizar o grau de familiaridade dos pesquisados sobre esse referencial teórico. A partir desse momento, foi realizado o questionamento específico sobre sua percepção para cada um dos cinco aspectos que compõe o modelo de design attitude. A partir do momento em que ocorria a ampla reflexão sobre cada um dos cinco aspectos, iniciou-se a exploração das conexões possíveis entre o design attitude e o design estratégico. A primeira questão objetiva encaminhada aos entrevistados foi sobre a aplicação do modelo de design attitude de Michlewski $(2008,2015)$ para o design estratégico, buscando identificar se existia algum dos aspectos do design attitude que não se enquadrariam na visão do design estratégico. Posteriormente, o questionamento buscava identificar elementos do design estratégico não contemplados no modelo de design atitude.

\section{Resultados e Discussão}

$\mathrm{Na}$ análise individual de cada um dos aspectos, por parte dos especialistas, tivemos informações sob diferentes perspectivas que detalharemos na sequência. Todos os entrevistados foram provocados inicialmente a trazer a sua percepção em relação a cada um dos cinco aspectos específicos do design attitude para só depois, identificar esses aspectos em relação a visão particular de cada um do design estratégico. Detalharemos as percepções dos entrevistados nos subitens a seguir.

\subsection{Aspecto 1: abraçando a ambiguidade e a incerteza}

Para simplificar a análise do discurso sobre "abraçando a ambiguidade e a incerteza" foi importante considerar duas diferentes perspectivas que aparecem mescladas nas entrevistas dos especialistas. Uma está relacionada à crítica aos modelos lineares do mercado de trabalho e da academia. A outra, a partir da reflexão mais descontextualizada e mais aderente à proposta do modelo do design attitude de Michlewski $(2008,2015)$ que queremos analisar e que se aproxima da natureza do design. A visão específica em contexto no qual não existe espaço para o pensamento divergente é naturalmente a base de parte significativa das entrevistas. É genuinamente difícil para os entrevistados analisar uma visão sobre "abraçar a ambiguidade e incerteza" como um aspecto do design attitude sem fazer crítica aos modelos tradicionais, especialmente da indústria de produtos e/ou serviço, em que espaços para a ambiguidade e a incerteza são incomuns.

É interessante observar nas entrevistas que existe tensionamento entre os modelos vigentes nas empresas e/ou Escolas de Design e aquilo que se pretende analisar, o "abraçar a ambiguidade e a incerteza" como um dos aspectos do design attitude. A maior dificuldade para os entrevistados ao falar sobre tal aspecto foi a necessidade de abstrair a contextualização de tudo aquilo que foge à natureza do design dentro das organizações. Em geral, o discurso dos entrevistados inicia impregnado das experiências e em um repertório pautado pelos contextos clássicos das organizações rígidas ou, eventualmente, da complexidade e dos esforços na construção de um espaço para o pensamento divergente dentro desses modelos. Aspectos relacionados à cultura do design, mesmo em organizações, tendem a exigir esse esforço de abstração.

Designers, em geral, trazem o modelo abdutivo em oposição ao modelo indutivo ou dedutivo para solução de problemas. A diferença entre as formas de aproximação envolve o nível de certeza. Aplicando um método abdutivo, a solução de problemas significa que você não tem conhecimento das incertezas da situação, mas está preparada para mover em frente apesar das incertezas. 0 design attitude abraça ambiguidade buscando a descontinuidade e tomando risco de forma corajosa, agrupados e pulando no espaço desconhecido. Esses atributos têm a capacidade de desbloquear o sucesso de uma organização. (MICHLEWSKI, 2015). O design attitude normaliza a 
ambiguidade, a incerteza e a descontinuidade como componentes ordinários do cotidiano workflow de trabalho. Isso se conecta com o que testemunhamos no agitado e sempre transformado mercado. Como resultado, cria-se um ambiente no qual soluções novas e transformadoras podem emergir.

\subsection{Aspecto 2: engajando através da empatia profunda}

O segundo aspecto do modelo de Michlewski $(2008,2015)$ não se refere a empatia na forma mais simples. A visão genérica de nos colocarmos no lugar do outro é entendimento básico e insuficiente para compreender a proposta de empatia profunda a que se refere o autor para o design attitude. Sabemos que empatia é uma característica humana vital, mas o design attitude não trata como característica individual, predisposição ou grau de sensibilidade emocional. E, sim, como maneira de fazer as coisas por um grupo de pessoas e/ou organizações. (MICHLEWSKI, 2008, 2015). As entrevistas com os especialistas levantaram elementos importantes que ampliam a discussão sobre esse aspecto e enriquecem o debate sobre o conceito de empatia.

As entrevistas com os docentes para tratar do aspecto 2 do design attitude nos traz uma fotografia genérica interessante. Podemos dizer que os entrevistados, de forma geral, aceitam a plena da empatia como fundamento do design attitude e da teoria do design. Naturalmente, diferentes dimensões da empatia apareceram ao longo das entrevistas: a empatia como o auge do prazer e da explosão estética, a empatia como emoção, como habilidade social, como comportamento, entre outras.

Conforme já mencionamos, o design attitude não lida com a empatia de forma individualizada, ou no campo das emoções, mas como um jeito de fazer as coisas em determinado grupo de pessoas e muito particularmente nas organizações.

É importante reforçar que é empatia profunda, no contexto do design atitude, não é simples ferramenta, nova metodologia ou forma de observar o consumidor diferenciado. É, sim, uma crença profunda abraçada e incluída na prática de gerenciar projetos transformadores. É, sobretudo, relativo à forma como as decisões são feitas dentro das organizações. Finalmente, para funcionar, empatia profunda requer mente aberta e algum grau de ingenuidade e leveza que não são todas organizações e/ou líderes que estão preparados ou tem condições para atuar dessa forma. (MICHLEWSKI, 2015).

\subsection{Aspecto 3: abraçando o poder dos cinco sentidos}

Talvez entre os aspectos do design attitude, esse tenha sido o que gerou menor grau de conexão com os entrevistados. Na análise das entrevistas, percebemos também que para esse aspecto existe maior divergência entre os padrões de respostas. A razão talvez seja que exista percepção natural dos cinco sentidos como um valor do design, mas ao mesmo tempo sua tangibilização é de razoável complexidade. É também bastante lógico que a visão seja o sentido com maior relevância para os entrevistados, em relação aos outros, quando se fala da natureza do design. De qualquer sorte, parece claro que um projeto de design nas organizações está além da visão exclusiva de racionalidade e que explorar os cinco sentidos responde a necessidade de realizar projetos que possam afetar também o campo das emoções.

Vários elementos foram trazidos pelos entrevistados em relação ao terceiro aspecto do design attitude. Percepções como um segundo nível sensorial, racionalidade $\mathrm{x}$ sensorialidade, construção de experiências a partir dos sentidos, experiência de marcas e visão sobre os sentidos dominantes são elementos de destaque na visão dos docentes entrevistados sobre "abraçando o poder dos cinco sentidos". 
Segundo Michlewski (2015), designers são treinados e motivados para usar os cinco sentidos. Eles se sentem confortáveis no conflitado mundo dos estímulos multimodais. Por outro lado, é incomum os gestores utilizarem diferentes sentidos para a inspiração. Eles precisam aprender a abraçar a multimodalidade das experiências. No mundo dominado pelos softwares e por interfaces de toque, designers e gestores devem ativamente procurar os múltiplos sentidos para engajar usuários e criar conexões verdadeiras com as pessoas.

\subsection{Aspecto 4: paixão por dar vida às ideias}

As oito entrevistas com os especialistas para tratar do aspecto 4 do Design attitude tiveram elementos importantes. A facilidade com que entrevistados se identificaram com esse aspecto reforça a força da "paixão por dar vida as ideias". Esse aspecto é entendido de imediato pelos entrevistados como parte de todo processo de construção mais visceral da cultura do design, pois estão totalmente relacionados com a gênese do processo criativo no design. De forma geral, os entrevistados se alinham com Michlewski (2015) quando a autor afirma que dar vida às coisas (ideias) é, acima de tudo, o núcleo da profissão dos designers.

É muito importante entender como, orientado pelo aspecto 4 do design attitude, o processo de design pode dar vida às ideias e ir além, transformando o processo de design efetivamente em um combustível da inovação dentro das organizações.

Cabe destacar três aspectos genéricos, associados ao quinto aspecto do design attitude, que aparecem nas entrevistas dos especialistas:

1. A visão de dar vida as ideias não se restringe a mostrar aos outros, mas também a estabelecer importante e dinâmico diálogo do designer com a materialização da sua ideia, que só a representação concreta pode trazer. Ou seja, é um processo coletivo, mas é também individual.

2. A irreverência e o humor se articulam de forma verdadeira com um processo de empatia profunda, objeto do aspecto 2 do design attitude.

3. A capa da criatividade e aparente insanidade, metáfora usada por Michlewski (2015), vem sendo vestida pelas metodologias instrumentais do design thinking e ocupando espaço relevante nas organizações.

\subsection{Aspecto 5: criando novos significados a partir da complexidade}

Os designers normalmente lidam com problemas complexos, buscando harmonia entre duas coisas intangíveis: algo que ainda não foi projetado, em um contexto que não se consegue descrever propriamente.

Criar significados a partir da complexidade não é tema simples e não podemos cair na armadilha de tentar simplificá-lo. As entrevistas com os especialistas nos confirmam a importância do quinto e último aspecto do modelo de design attitude de Michlewski $(2008,2015)$, indicando perspectivas diferentes em relação à interpretação de como os designers lidam com a complexidade e reforçando a visão de articulação entre todos os aspectos do design attitude. A consolidação de significados multidimensionais valoriza o papel dos designers nas organizações, dada a tarefa de conciliar diferentes objetivos operacionais. Ele aponta para a capacidade de operar em um loop analítico-sintético, a fim de alcançar equilíbrio entre coesão interna e satisfazer as restrições práticas. Em outras palavras, "os designers dominam o processo de design abrangente que é uma integração rica e complexa do científico, do sensual, do intelectual e do intuitivo". (FRIEDMAN, 2016, p. 199). 
O processo de criação de projetos é, muitas vezes, associado à complexidade da resolução de problemas mal estruturados e abertos. Os problemas de design são, de forma geral, bastante incertos, incompletos e, muitas vezes, carregados de contradições. (SCALETSKY, 2016). Os designers convivem bem com problemas complexos. Dessa forma, trabalhar a construção de significados a partir da complexidade é mais natural para os profissionais do design do que em outras profissões. (MICHLEWSKI, 2015). O último aspecto do design attitude é certamente o mais holístico de todos e o que desafia mais os entrevistados a um processo reflexivo sobre a natureza do design, não só da atividade projetual em si, mas fundamentalmente do seu contexto.

As entrevistas reconhecem o aspecto 5 como fundamental ao modelo do design attitude e discorrem sobre diferentes perspectivas que vão do ambiente tecnológico às formas de ressignificação, dando maior importância ao designer como protagonista no processo humano de reconhecimentos de símbolos e produção de significados.

\subsection{Design atitude e Design Estratégico: convergências e divergências}

O modelo do design attitude tem cinco aspectos que foram, na visão dos especialistas, plenamente aceitos quando falamos de design estratégico. Entretanto, algumas questões foram observadas como aspectos que deveriam compor o modelo do design attitude sempre que estivermos nos referindo ao design estratégico.

Foram levantados seis aspectos decorrentes das subcategorias provenientes da análise de conteúdo. As observações dos especialistas se articulam entre si e, algumas vezes, propõem dimensões um pouco diferentes para o mesmo aspecto, possibilitando a geração de um modelo ampliado de design attitude ou um modelo de atitudes de design estratégico. São eles: construção coletiva, visão metaprojetual, ecologias, projeção de cenários, enfoque na organização e na estratégia e processo projetual. Desses elementos, foram desconsiderados aqueles que foram citados apenas por um dos entrevistados, supondo que este aspecto tem visão mais particular e isolada. Depois, podemos analisar individualmente cada um dos aspectos que tiveram pelo menos duas citações, descritos a seguir.

\subsubsection{Construção coletiva}

Nas entrevistas com os especialistas, o aspecto "construção coletiva" de design ou variações - como trabalho coletivo, processo coletivo, projeto coletivo, visão coletiva, co-design - foram citados por cinco dos oito entrevistados como um ponto que deveria compor o design attitude quando nos referimos ao design estratégico. Várias perspectivas da construção coletiva no design estratégico foram trazidas pelos entrevistados em diferentes dimensões e panoramas. Entretanto, independentemente das diferentes interpretações sobre as dimensões do design estratégico em que se colocam (plano operacional, plano estratégico ou plano político), em qualquer condição a visão coletiva é tratada como condição essencial.

Além dos especialistas, a construção coletiva se apresenta também como um dos pilares do design estratégico na visão de seus principais autores, como Meroni (2008), que afirma que design estratégico é fazer co-design. Essa visão coletiva é reforçada por Zurlo (2010), que afirma que este suporta a ação estratégica graças às próprias capacidades, e finaliza a própria operacionalidade na geração de um efeito de sentido operando a partir de âmbitos coletivos. Segundo o autor, o design estratégico torna-se determinante para criar sentido de agir da organização, que motiva os atores envolvidos na rede de projeto e os demais atores que participam do projeto organizacional. A construção coletiva dentro das organizações é também influenciada pela visão do design estratégico como suporte a inovações sociais, que têm em Manzini um dos seus principais pensadores, em uma 
visão sempre pautada pelos processos participativos de design.

Conforme vimos na análise das entrevistas, a construção coletiva requer alta capacidade de negociação. Disso depende o sucesso de qualquer projeto a partir dessa abordagem. A forma difusa de operar e a relação com diferentes stakeholders determinam a necessidade de fazer do diálogo uma ferramenta fundamental para essa construção em um processo comunicativo e relacional. Meroni (2008) o denomina de diálogo estratégico, que consiste em uma constante nessa abordagem de design em todo o projeto: do problem setting ao problem solving. O contrabriefing é uma questão de diálogo estratégico; co-design é uma questão de diálogo estratégico, visões compartilhadas são questões de diálogos estratégicos. Para Zurlo (2010), a estratégia é diálogo e confronto, conversa e negociação entre múltiplos atores, e visa alcançar o sucesso, um resultado que tem sentido para alguém.

\subsubsection{Visão Metaprojetual}

A abordagem metaprojetual prevê a evolução de uma reflexão acerca do projeto em desenvolvimento, paralela e para além dele, que fundamente e justifique que o projeto em si. Justifique em relação ao contexto que o originou e em relação ao cenário para o qual é destinado. Dessa forma, estimula também a reflexão e a conscientização dos atores envolvidos no projeto a respeito do seu significado. (FRANZATO, 2011).

Como no planejamento estratégico, também no design estratégico o pensamento por cenários é determinante. (MORAES, 2011). Os cenários que orientam o design (MANZINI, 2003 apud FRANZATO 2014), componente essencial de todos os processos metaprojetuais, auxiliam a construção, a antecipação e a discussão crítica das estratégias, logo a sua avaliação, escolha e prática. Desse modo, os cenários permitem definir as estratégias das organizações e, a partir delas, sintonizar os seus processos e o desenvolvimento dos sistemas produto-serviço a serem ofertados. (FRANZATO, 2014). Existem vários autores que falam de uma abordagem em favor da inovação. Segundo Freire (2014), a proposta de Manzini e Jegou (2006) para o uso na construção de cenários é a que mais se aproxima ao que Zurlo (1999; 2010; 2012 apud FREIRE) propõe em seus trabalhos.

É interessante observar que Zurlo (2010) já identificava, quando se referia à operacionalização da construção de cenários e de visões estratégicas para as organizações, a necessidade do diálogo entre o design e a gestão. É exatamente esse o papel que estamos fazendo em nossa pesquisa: analisar o design attitude e fazê-lo dialogar com o design estratégico. No modelo do design attitude de Michlewski (2008, 2015), jamais aparece os termos metadesign ou metaprojeto. Todo seu esforço no sentido de entender por meio de pesquisa o que constitui a natureza do processo criativo da cultura dos profissionais de design não inclui elementos que apontem, objetivamente e de forma importante, para uma visão metaprojetual.

\subsubsection{Itens citados e não incluídos no modelo ampliado}

Dois outros itens foram citados por mais de um especialista - projeção de cenários e enfoque na organização e na estratégia -, porém entendemos que não apresentam homogeneidade conceitual para se apresentarem como um novo aspecto do modelo ampliado do design attitude para o design estratégico. São eles:

a) Projeção de cenários: o item "projeção de cenários" ou "projeção de cenários futuros", foi incluído como subcategoria na categorização dos aspectos do design estratégico, não considerados no design attitude pelos especialistas. Entretanto, entendemos que esses pontos estão incluídos dentro da abordagem analisada no item anterior (visão metaprojetual) e que, por meio da visão, passou a compor o modelo ampliado do design attitude. Ou seja, buscando maior 
homogeneidade conceitual dos aspectos do modelo ampliado, optamos por ficar apenas com a visão entendendo que a projeção de cenários está incluída nesse espaço.

b) Enfoque na organização e na estratégia: toda a origem do conceito de design attitude está relacionado com o impacto do design e dos designers nas organizações. A referência conceitual, como já nos referimos, está no trabalho de Boland e Collopy (2002). O modelo do design attitude (MICHLEWSKI, 2015), por sua vez, foi todo concebido para explorar com profundidade o impacto do design e dos designers nas organizações. A pesquisa foi feita em organizações onde o design ou designers profissionais têm significativa presença e influência.

Segundo Michlewski (2015), os designers impactam as organizações espalhando seus valores, suas atitudes e seu jeito próprio de fazer as coisas. Os designers são invasores do mundo corporativo a favor da transformação, mudando também, no nível estratégico, a cultura organizacional. Dessa forma, entendemos que o aspecto enfoque na organização e na estratégia está plenamente coberto pelo modelo de design attitude, proposto por Michlewski $(2008,2015)$, e entendemos que não seria necessário, incluí-lo no design attitude ampliado. Na imagem a seguir, apresentamos a a representação do modelo ampliado do design attitude para o design estratégico com a estrela de 7 pontas, representando os cinco aspectos originais, mais os dois aspectos adicionados (construção coletiva e visão metaprojetual):

Figura 2 - Modelo de atitudes de design ampliado

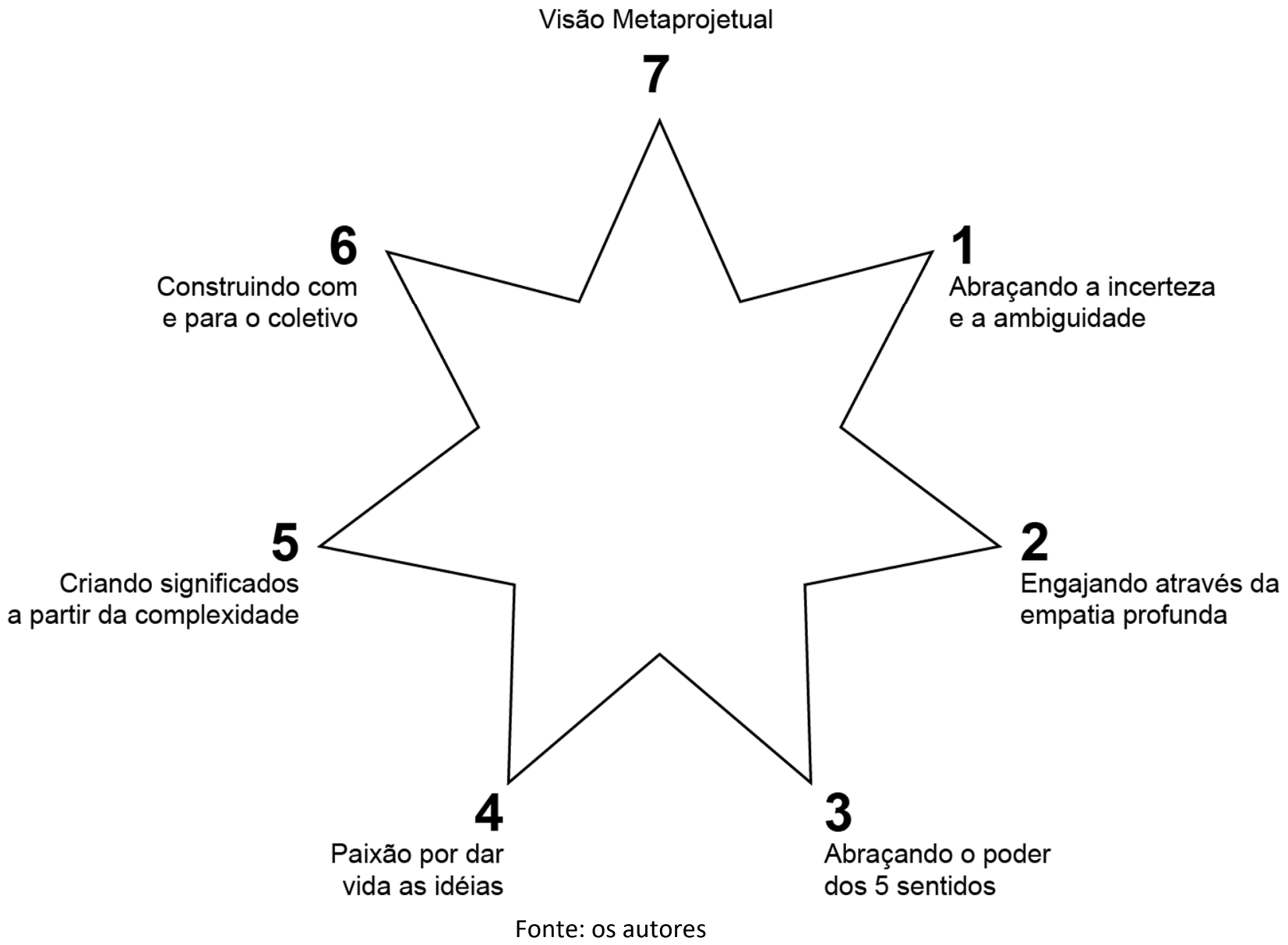




\section{Considerações Finais}

Este estudo teve como objetivo identificar e discutir as atitudes de design estratégico e suas relações com o modelo de design atitude proposto por Michlewski $(2008,2015)$. Na opinião dos especialistas em design estratégico entrevistados, o modelo do design attitude foi considerado apropriado para as premissas teóricas do design estratégico em seus cinco aspectos. Ou seja, nenhum dos oito especialistas entrevistados desaconselhou a utilização de qualquer um dos aspectos que compõem o design attitude para o design estratégico.

O modelo ampliado do design attitude foi proposto a partir da análise das entrevistas individuais com os especialistas e conforme a expressão da visão e do pensamento coletivo deles sobre quais aspectos deveriam ser incluídos no modelo de design attitude ampliado para o design estratégico. Após análise e busca por homogeneidade conceitual, entendemos que construção coletiva e a visão metaprojetual seriam os dois elementos que deveriam compor o modelo ampliado.

Neste trabalho, foi desenvolvido o diálogo entre as escolas de Administração e de Design, produzindo um modelo de atitudes que tem raiz na primeira (BOLAND; COLLOPY; LYYTINEN; YOO, 2008, MICHLEWSKI, 2008, 2015) e ampliação proposta pela segunda, que se apresenta como contribuição teórica para o design estratégico.

A ausência de referências objetivas sobre o designer estratégico na ação projetual coletiva de formulação de estratégias, dentro das organizações, se afasta da visão de performance desses coletivos, o que acaba estabelecendo uma barreira para a evolução do design estratégico nas organizações, que têm objetivos de negócios. O modelo de design attitude ampliado para o design estratégico é um modelo teórico que ocupa essa lacuna. Entretanto, como qualquer modelo teórico precisa ainda ser validado e evoluído.

Conforme mencionamos na fundamentação teórica, para Buchanan (2015), o pluralismo do pensamento do design pode atuar em diferentes dimensões dentro da estrutura organizacional, desde o processo cognitivo básico, passando pelo questionamento criativo, avançando na implementação de novos modelos até a transformação inovadora e criativa do espírito e da cultura da toda organização. 0 modelo de design attitude ampliado se posiciona exatamente na dimensão do questionamento criativo e na ação de implementação de novos modelos que afetam as definições estratégias e que projetam as transformações das organizações.

Segundo Buchanan (2015), o design attitude foca na cultura profissional do design, nas atitudes e nos valores que estão atrás de todo trabalho criativo. Valores e Atitudes que são a fundação da imaginação e da criação no design. No nosso estudo, podemos dizer que a proposta do modelo ampliado do design attitude se preocupa em questionar quais são efetivamente os valores e aspectos que fundamentam a ação criativa do designer estratégico e qual a natureza da contribuição dos designers estratégicos. Entendido isso, temos um modelo com sete aspectos que pode ser utilizado de forma metodológica apoiando a evolução do design estratégico dentro das organizações de forma objetiva, mas sem se afastar da visão sistêmica e coletiva e sem deixar de aceitar a incerteza, a ambiguidade, a imprevisibilidade, a aleatoriedade e a contradição como base de seu processo de design.

\section{Referências}

BOLAND, COLOPY; LYYTINEN; YOO, 2008 Managing as designing: lessons for organization leaders from the design practice of Frank O. Gehry. Design Issues, Vol. 24, n. 1, 2008. 
BUCHANAN, Richard. Prefácio. In: MICHLEWSKI, Kamil. Design attitude. Farnham: Gower Publishing Company. 2015

BUCHANAN, Richard. Worlds in the making: design, management and the reform of organizational culture. She Ji: the journal of design, economics and innovation. Issue 1, autumn, 2015.

BUCHANAN, Richard. Design and organizational change. Design Issues, Vol. XXIV, N. 1, 2008.

DESERTI, Alessandro; RIZZO, Francesca. Design and the culture of enterprises. Design Issues. v.30 n.1, 2014.

FRIEDMAN, Ken. Three Thousand years of designing business and organizations. In: JUNGINGER, Sabine; FAUST, Junger. Designing Business and Management. EUA: Bloomsbury Academic, 2016.

FRANZATO, C. Design estratégico aplicado: uma experiência colaborativa entre universidade e empresa. Capítulo 1.1, Design Estratégico, 2014.

FRANZATO, C. et al. Inovação e Cultural e Social: design estratégico e ecossistemas criativos. In: FREIRE, K. (org). Design Estratégico para Inovação Cultural e Social. São Paulo, Kazuá, 2015, p. 157182.

FRANZATO, C. O design estratégico no diálogo entre cultura de projeto e cultura de empresa. Strategic Design Research Journal, 2010.

FRANZATO, C.; VELASQUES, Taline Sabany; GAUDIO, Chiara Del. Ecossistemas criativos: relações colaborativas e ação projetual nos coletivos criativos informais. International Journal of Knowledge Engineering and Management. V. 4, n. 10, 2015.

FREIRE, Karine. Design estratégico: origens e desdobramentos. In: 110 Congresso Brasileiro de Pesquisa e Desenvolvimento em Design, 2014, Gramado. Anais do 110 Congresso Brasileiro de Pesquisa e Desenvolvimento em Design. São Paulo: Editora Edgard Blücher, 2014.

FREIRE, Karine. From strategic planning to the designing of strategies: A change in favor of strategic design. Strategic Design Research Journal, 2017, v.10, n.3, May-August, p. 91-96. 2017.

JACOBY, R.; RODRIGUEZ, D.. Innovation, growth, and getting to where you want to go. In: LOCKWOOD, Thomas; WALTON, Thomas. Building Design Strategy: Using Design to Achieve Key Business Objectives. NY, EUA: Allworth Press, 2008.

MANZINI, Ezio. Strategic Design for Sustainability: instruments for radically oriented innovation. In: JÉGOU, F; MANZINI, E. Sustainability everyday: scenarios of urban life. Milano: Edizioni Ambiente, 2003.

MANZINI, E.; JÉGOU, F. Design degli scenari. In: BERTOLA, P.; MANZINI, E.(org.). Design multiverso: appunti di fenomenologia del design. Milano: Edizione POLIdesign, 2014.

MANZINI, Ezio. Making Things Happen: Social Innovation and Design. Design Issues. v.30 n.1, 2014.

MAURI, F. Progettare progettando Strategia. Milano: Masson S.p.a., 1996.

MERONI, Anna. Strategic design: where we are now? Reflection around the foundations of a recent discipline. Strategic Design Research Journal, v.1, n.1, Dec, p. 31-38. 2008.

MICHLEWSKI, Kamil. Uncovering design attitude: Inside the Culture of Designers. SAGE

Publications, 2008. Disponível em:

<http://journals.sagepub.com/doi/pdf/10.1177/0170840607088019>. Acesso em: 30 mar. 2017. 
MICHLEWSKI, Kamil. Design attitude. Farnham: Gower Publishing Company, 2015.

MICHLEWSKI, Kamil. Toward na understanding of the role the culture of designers can play in organizations. Doutorado (tese), Northumbria University, Reino Unido, 2006. Disponível em: <http://nrl.northumbria.ac.uk/1827/1/michlewski.kamil_phd.pdf>. Acesso em: 30 mar. 2017.

MORAES, D. Metaprojeto como modelo projetual. In: MORAES, D; DIAS, R.A.; BOM CONSELHO, R. (org). Método. Barbacena: EdUEMG, 2011.

MURATOVSKI, Gjoko Richard. Paradigm Shift: Report on the New Role of Design in Business and Society. She Ji: the jornal of design, economics and innovation. Vol. 1, n. 2, 2015.

SCALETSKY, Celso. Design estratégico em ação. São Leopoldo: ed. Unisinos, 2016.

SCHÖN, D. A. The reflective practitioner. New York: Basic Books, 1983.

SIMON, H. A. The sciences of the artificial. MIT Press, 1969.

ZURLO, Francesco. Design Stratégico. In: XXI Secolo, vol. IV, Gli spazi e le arti. Roma: Enciclopedia Treccani. 2010. 